\title{
Dynamic behavior modeling of cigarette smoke particles inside the car cabin with different ventilation scenarios
}

\author{
* E. M. Saber; M. Bazargan \\ Department of Mechanical Engineering, K. N. Toosi University of Technology, Tehran, Iran
}

Received 12 November 2010; revised 9 June 2011; accepted 5 August 2011

\begin{abstract}
Dynamic behavior of cigarette smoke particles inside the cabin of cars is investigated and the respirable suspended particles concentration during and after smoking cigarette is predicted in this study. This model is based on mass balance equations. Mechanisms of deposition on the surfaces and the exchange of air in the cabin are considered as sinks for emitted particles. The coagulation is accounted as a sink for smaller particles and as a source for larger particles. The various scenarios of smoking in the cars available in the literature are simulated in this study. Good agreement between the results of the present model and the experimental data, as well as the predictions of other available models, is achieved. The mean respirable suspended particle concentration in different scenarios is estimated and compared with Environmental Protection Agency's health-based standards in order to specify the situations with respirable suspended particles concentrations exceeding the allowable limits. The results show that the concentration of particles due to the smoke of a single cigarette in a stationary medium sized car with the air conditioner off is $33.6 \mu \mathrm{g} / \mathrm{m}^{3}$ and nearly reaches the limits appointed by the Environmental Protection Agency for a $24 \mathrm{~h}$ incremental exposure $\left(35 \mu \mathrm{g} / \mathrm{m}^{3}\right)$. Corresponding values for moving cars have also been calculated and compared with the standards.
\end{abstract}

Keywords: Air change rate; Environmental Protection Agency; Mass balance; Particle coagulation; Particle deposition; Resiprable suspended particles

\section{INTRODUCTION}

The sources of air pollution are various. Air pollution caused by industries and vehicles is an important threat for the respiratory system of the residents of big cities (Omidvari and Nouri, 2009; Salam et al., 2011). Among the air pollutants, Respirable suspended particles (RSP) are more scrutinized because they can penetrate deep and deposit on the lungs of humans. Their aerodynamic diameters are usually less than $2.5 \mu \mathrm{m}\left(\mathrm{PM}_{2.5}\right)$. Tang and Wang (2006) measured the exposure of $\mathrm{PM}_{2.5}$ to the driver of a car during traffic congestion for different vehicle categories and reported that the $\mathrm{PM}_{2.5}$ concentration with background contribution ranged from 94 to $209 \mu \mathrm{g} / \mathrm{m}^{3}$. These concentrations, however, as will be shown later, can be much smaller than the maximum $\mathrm{PM}_{2.5}$ concentration which may occur in a car by smoking a cigarette. Environmental tobacco smoke (ETS) emission is a major source of RSP in enclosed areas, which still requires further investigation.

*Corresponding Author Email: bazargan@kntu.ac.ir Tel.: +9821 84063 239; Fax: +9821 88677274
Many studies in the past decades have measured and modeled the pollutants of cigarettes in different indoor locations. Public lounges, restaurants, taverns, bars, hospitals, and offices are among the most common locations in past studies (Klepeis et al., 1996; Ott et al., 1996; Phillips et al., 1998; Maskarinec et al., 2000; Klepeis and Nazaroff, 2006). There still remain indoor locations for which available studies are not adequate to accurately evaluate the concentration of the cigarette smoke particles as a function of time for various particle sizes. A good example is the cabin of cars. The high RSP concentration after smoking a cigarette in a car poses a threat to the health of nonsmokers, especially children. Because of the limited volume in which the cigarette smoke disperses, the concentration of cigarette pollutants in cars is expected to be higher than in other indoor places. A recent experimental investigation published by the Ontario Tobacco Research Unit (Sendzik et al., 2009) showed that smoking just a single cigarette in a car can lead to a peak level of tobacco smoke concentration that 
exceeds by several times the amount of tobacco smoke concentration found in the smokiest bars and restaurants.

Table 1 summarizes the experiments conducted on the $\mathrm{PM}_{2.5}$ concentration level after smoking cigarettes in cars from four published articles. As can be seen from the table, different ventilation settings and window positions of cars lead to different RSP concentrations. Even under similar conditions, the reported ETS emission profiles may differ. That can be caused by various parameters such as the different procedures of each experiment and the differences in types and brands of the cigarettes. The emission rates may even vary from one smoker to another as the composition of the smoke is affected by the frequency and duration of the puffs and how the smoker inhales and exhales.

The notations SS and MS used in Table 1 refer to sidestream and mainstream smokes, respectively. The mainstream is the smoke inhaled and exhaled by taking a puff on a lit cigarette and the sidestream is the smoke emitted from the burning end of the cigarette on its own without any interference made by the smoker. The cigarette consumption time is variable for each experiment and is in the range of 5 to $8 \mathrm{~min}$ when smoked by a real smoker and may last up to $10 \mathrm{~min}$ when smoldering on its own. The highest level of concentration shown in Table 1 exceeds $5000 \mu \mathrm{g} / \mathrm{m}^{3}$ and corresponds to a parked car with closed windows and no ventilation (Sendzik et al., 2009). Note that this RSP concentration is much higher than those caused by other sources such as tailpipe emissions of neighboring cars during traffic congestion (Fruin et al., 2004; Pirjola et al., 2004; Tang and Wang, 2006).

Most of the mathematical models presented to predict the pollutant concentration in enclosed areas are based on the mass balance equation. Nazaroff and Cass (1989) developed a numerical model to simulate the evolution of particle size distributions and to predict the concentration of different particle sizes as a function of time. They validated their results using the experimental data of Offermann et al. (1985) in a room with a low air change rate of $0.05 \mathrm{ACH}$ (Air Changes per Hour). Later, this model was incorporated with an analytical model of the two-zone environment (Miller and Nazaroff, 2001) and linked with a multizone airflow model (Sohn et al., 2007) to predict ETS particle transport in multi chambers.
Ott et al. (1992) developed a Sequential cigarette exposure model (SCEM) to calculate the pollutant concentration time series in well-mixed environments. They validated the model predictions with their experiments for carbon monoxide and RSP in a chamber and an automobile. The mathematical model of Ott et al. (1992) was extended later as a multiple-smoker model for predicting time-averaged pollutant concentration in public lounges (Klepeis et al., 1996) and incorporated with a mathematical trend correction term to estimate the RSP concentration in a sports tavern (Ott et al., 1996). In the current study, the behavior of cigarette smoke particles in chambers with high air change rates similar to those occurring in cars is simulated. The cigarette emission is taken into account as a source. Deposition on the surfaces and the exchange of air are considered as sinks. The coagulation of particles is considered as a sink for smaller particles and as a source for larger particles. This research was carried out from 2008 to 2010 at the K. N. Toosi University of technology in Tehran, Iran.

\section{MATERIALS AND METHODS}

Most of the presented models in literature for predicting the RSP concentration in enclosed areas are based on the mass balance equation and well-mixed assumption ( Nazaroff and Cass, 1989; Ott et al., 1992). Assuming uniform mixing of the pollutant emitted from a point source in large places like rooms and apartments can lead to considerable errors compared with measurements made several minutes after the smoking has stopped. However, in cars with closed windows, because of the limited space (usually ranged from 2 to $6 \mathrm{~m}^{3}$ ) the errors generated by this simplification are insignificant. The rate of the change in particle mass concentration for each size category is a result of all sources and sinks. The basis of this modeling is given by a first order differential equation as follows:

$$
\frac{d C_{i}}{d t}=\&_{g, i}-\&_{r, i}
$$

The index $i$ refers to the size categories starting from $i=1$ for the smallest particles to $i=\mathrm{n}$ for the largest category. The generation $\left(C_{g, i}\right)$ and removal $\left(C_{r, i}\right)$ rate for each size category is specified from the cigarette emission profile, ventilation rate, filtration efficiency, coagulation of particles and deposition rate on 
Int. J. Environ. Sci. Tech., 8 (4), 747-764, Autumn 2011

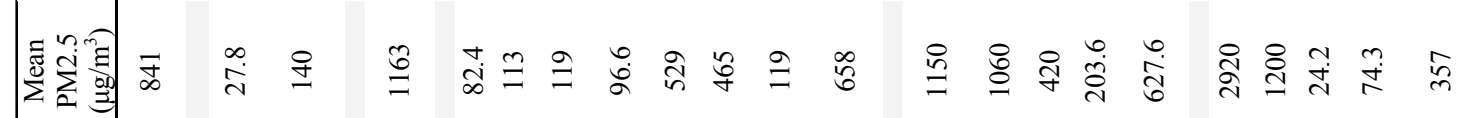

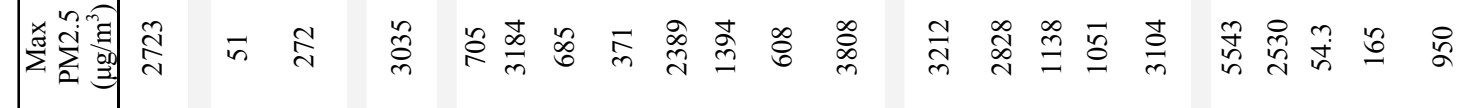

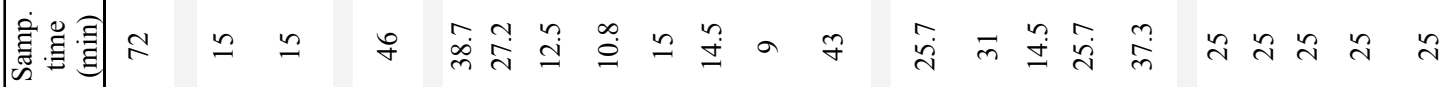
(n)

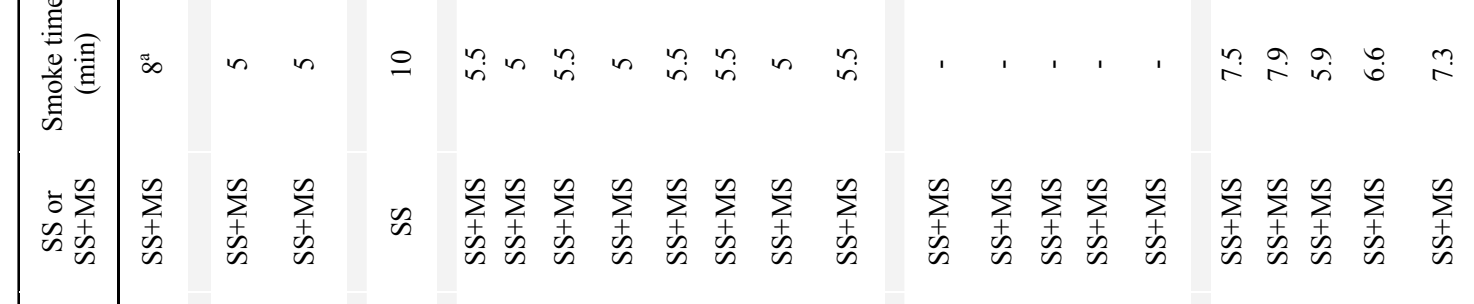
苞

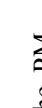

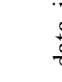

(1)

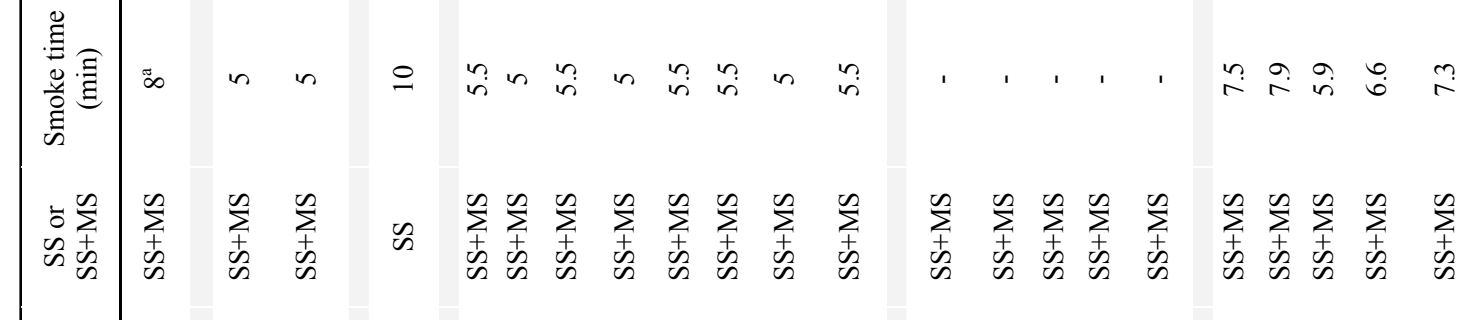

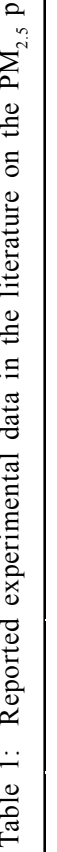
(4)

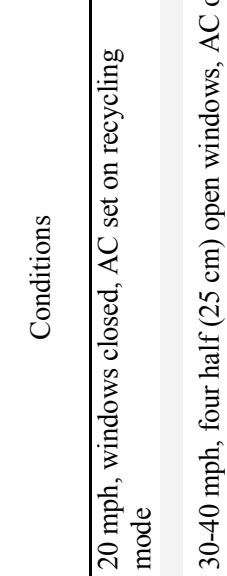

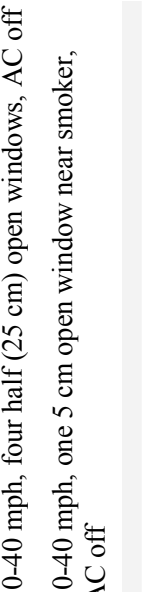

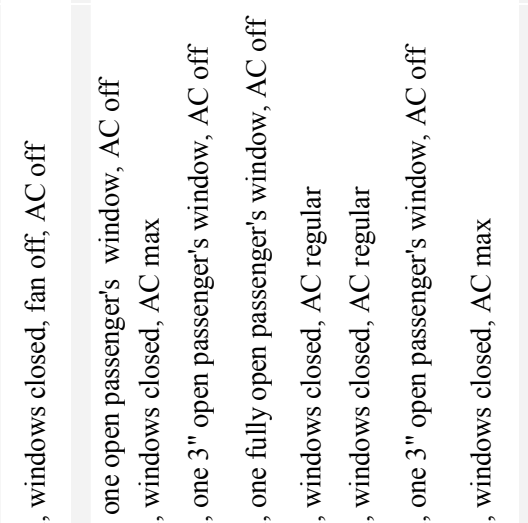

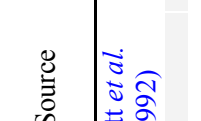

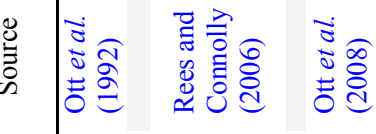

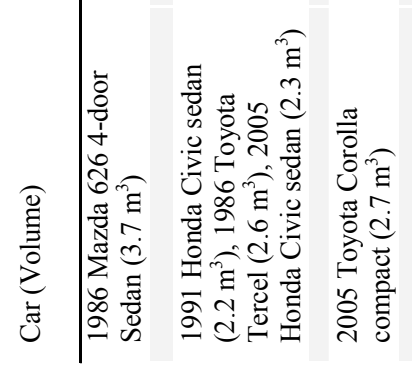

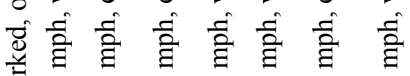

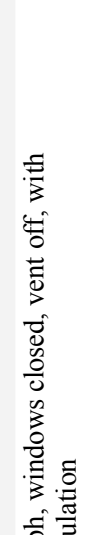

).

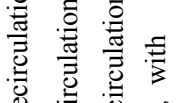

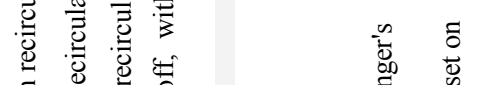

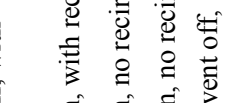

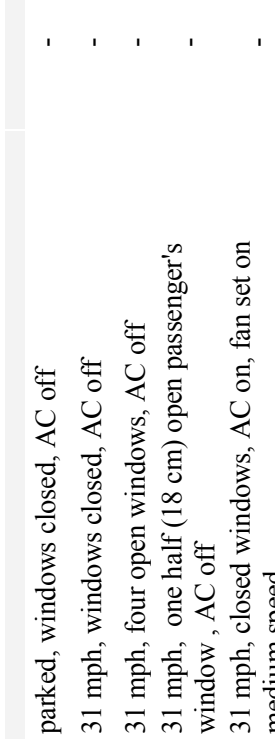

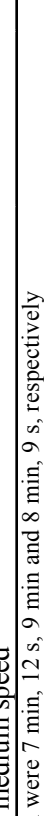


surfaces. The details of these parameters are discussed in the following sections.

\section{Cigarette RSP emission profile}

The main source term in the mass balance equation is the emission of RSP from the cigarette. Nazaroff and Klepeis (2003) have summarized the generation rates of RSP during smoking for cigars and cigarettes reported by various investigators. According to their report, the SS+MS mass emission rate during cigarette smoking varies from 0.76 to $3.6 \mathrm{mg} / \mathrm{min}$ in different studies. For example, the measured mass emission rates for the top 50 brands of cigarettes in the USA presented by RJ Reynolds Tobacco Company have been reported by Repace (2007) to vary from 7.5 to $22.5 \mathrm{mg}$ during 11 min of smoking. This corresponds to emission rates ranging from about 0.68 to $2.04 \mathrm{mg} / \mathrm{min}$.

Despite the fact that there are differences in values of ETS emission rates reported by various investigators, from a qualitative perspective, however, the emission profiles obtained from different studies seem to be demonstrating the same trend of variations of particle concentrations with particle sizes. In fact, once particle concentrations are plotted against the logarithmic scale of particle sizes, a normal distribution is observed. Two sets of data, one reported by Klepeis et al. (2003) and the other presented by Sextro et al. (1991) (reported in Nazaroff et al., 1993) seem to be among the most comprehensive ones. While both data sets follow a lognormal profile, a larger total amount of emission rate has been reported by the latter. To be more conservative and stay on the safer side in comparing the model predictions with the Environmental Protection Agency (EPA) allowable levels of ETS for indoor spaces, the data of Sextro et al. (1991) has been used in the present study to represent the size-resolved emissions data for ETS.

The cigarette RSP emission profile reported by Sextro et al. (1991) consists of the mass emission rate of 2.4 $\mathrm{mg} / \mathrm{min}$ with a mass median diameter of $0.48 \mu \mathrm{m}$ for sidestream plus mainstream smokes based on the experiments in which three cigarettes were smoked over a 6-h period. The distribution of the emission rate as a function of the particle size is shown in Fig. 1. The RSP emission range has been divided into 8 size categories and the size intervals are set in such a way that the mass of the largest particle in each category is greater than twice the mass of the smallest particle in that category. The emission rate profile is used as the source term to calculate the concentration of the particles in each size category according to the following equation.

$\frac{d C_{i}}{d t}=S_{E, i}=\frac{E_{i}}{V}$

Where $E_{i}(\mathrm{mg} / \mathrm{min})$ is the emission rate for each size category ( $i=1$ to $n), n$ is the number of size categories and $V\left(\mathrm{~m}^{3}\right)$ is the volume of the cabin.

\section{Ventilation and filtration}

The ventilation system and air exchange through the vents and windows of the cars act as the main sinks for cigarette pollutants. Selecting between the fresh air mode, passive ventilation or the recirculation mode are the key settings in most of the ventilation systems in cars and can influence the rate of air exchange especially in moving cars. The ranges of air change rates reported in literature for different car movement cases, window positions, ventilation conditions, fan settings and vent settings are summarized in Table 2. For example, for stationary cars with closed windows depending on the ventilation conditions, fan setting and vent setting of the cabin, the air change rate ranges from very small values close to zero up to $77.3 \mathrm{ACH}$. This variation in the air change rate of cars shows the influence of the ventilation settings on the exposure of the nonsmokers to cigarette pollutants in cars. The following equation is used to calculate the effect of the removal rate of the particles of a specific concentration category caused by ventilation and filtration:

$\frac{d C_{i}}{d t}=\frac{\eta_{i} Q_{\text {fresh }} C_{\text {out }, i}}{V}-\frac{Q_{\text {exit }} C_{i}}{V}-\frac{\eta_{i} Q_{r e c} C_{i}}{V}$

Where $c_{i}$ is the filtration efficiency for each size category which deals with the fresh air and recirculated air in the first and third terms of the right hand side of the equation respectively. Filtration efficiency is the ratio of number of separated particles in filter to the number of particles in the inlet air for a specified size of particles. The collection efficiency of Heating, Ventilation, and Air conditioning (HVAC) systems in a typical car is above $70 \%$ for $0.3 \mu \mathrm{m}$ particles (Reinhardt and Kobori, 2006). $C_{\text {Out }}\left(\mathrm{m}^{3} / \mathrm{min}\right)$ is the concentration of particles in fresh air. $Q_{\text {fresh }}\left(\mathrm{m}^{3} / \mathrm{min}\right)$ and $Q_{\text {exit }}\left(\mathrm{m}^{3} / \mathrm{min}\right)$ are the volumetric flow rates of fresh air and exiting air which are equal to each other. $Q_{\text {rec }}\left(\mathrm{m}^{3} / \mathrm{min}\right)$ is the volumetric flow rate of recirculation. 
Deposition model

A number of models have been proposed by various researchers to predict the rate of deposition of particles on indoor surfaces. The deposition model of Lai and Nazaroff (2000) has been widely applied and further developed in several studies (Thatcher et al., 2002; Lai, 2005; Lai and Nazaroff, 2005; Gao and Niu, 2007; Zhao and Wu, 2007). In another study, Lai and Nazaroff (2005) measured the deposition velocity of particles (in the range of $0.9-9 \mu \mathrm{m}$ ) onto smooth and rough vertical chamber surfaces and concluded that the effect of particle size is much larger than the effect of surface roughness. Thus, in the present study the surface of seats, the dashboard, the windows, the roof and the floor in cars are assumed to be smooth surfaces. The experiments of Lai and Nazaroff (2005) also indicated an increase of the deposition velocity for particles larger than $3 \mu \mathrm{m}$. That is while the predicted deposition velocity on smooth surfaces by the model of Lai and Nazaroff (2000) shows a monotonic decrease with the increase of particle sizes. Since cigarette smoke particles are usually smaller than $3 \mu \mathrm{m}$, implementation of the deposition model of Lai and Nazaroff (2000) is expected not generating any inaccuracy in this regard and seems to be well suited to the current study.
To calculate the deposition velocity of particles on interior surfaces of cars, the volume of the cabin and the area of the surfaces must be determined. A typical sedan automobile (a Daewoo Cielo car) has been used in this study. The dimensions of the car were measured simply by measuring tape. The interior space of the cabin was approximated by 25 bricks and prisms. The total volume of the cabin was estimated by simply adding the 25 volumes. To calculate the total area of the interior surface, those sides of the bricks and prisms that represent seats, windows, doors, the roof, the floor, and the dashboard of the car were considered. The results of the measurements show that the cabin volume of a Daewoo Cielo car is approximately $2.15 \mathrm{~m}^{3}$ and the total area of the interior surface is around 15.77 $\mathrm{m}^{2}$. These values indicate that the surface-to-volume ratio of the car under study is $A / V=7.33 / \mathrm{m}$. The share of each of the vertical, upward horizontal, and downward horizontal surfaces are $4.05 \mathrm{~V}, 1.64 \mathrm{~V}$ and $1.64 \mathrm{~V}$, respectively. Note that the slanted surfaces have been broken up into vertical and horizontal directions to facilitate calculation of the deposition rate. Note also that for enclosed areas with relatively high surface-to-volume ratios, like cabins of cars, the rate of deposition of the particles on interior surfaces can be quite significant.

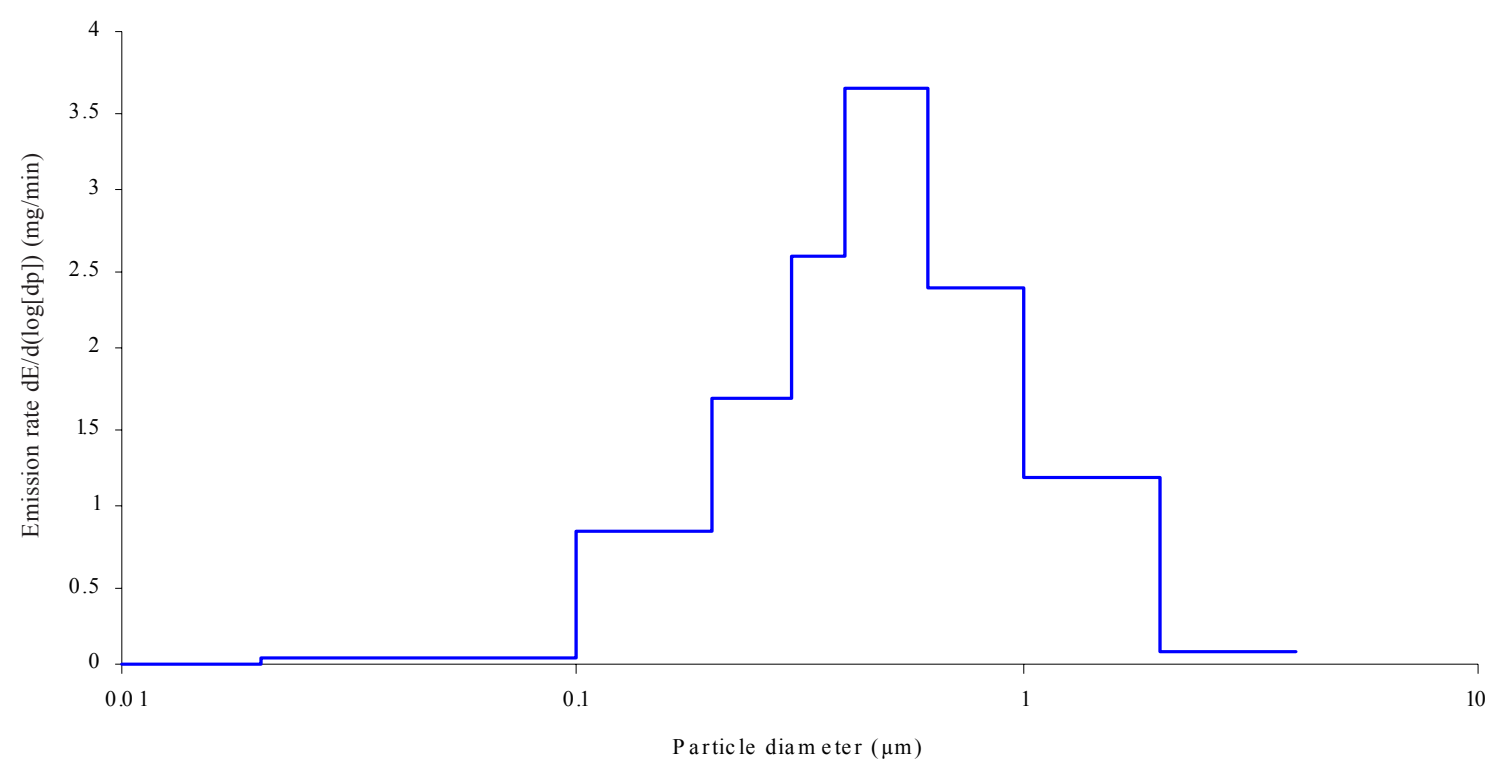

Fig. 1: Assumed RSP emission rate profile of sidestream plus mainstream (SS+MS) cigarette smoke based on the reported data of Sextro et al. (1991) 


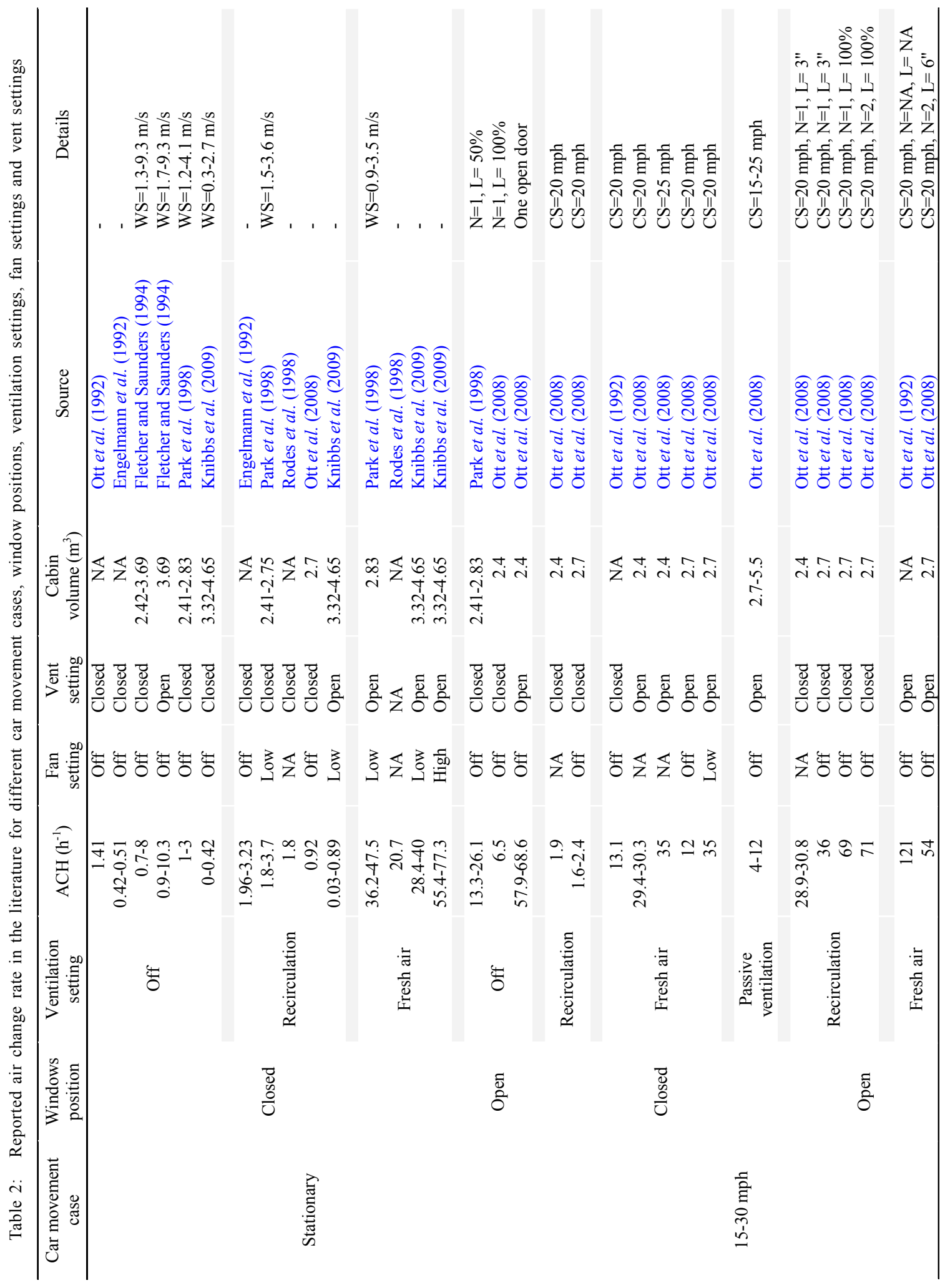




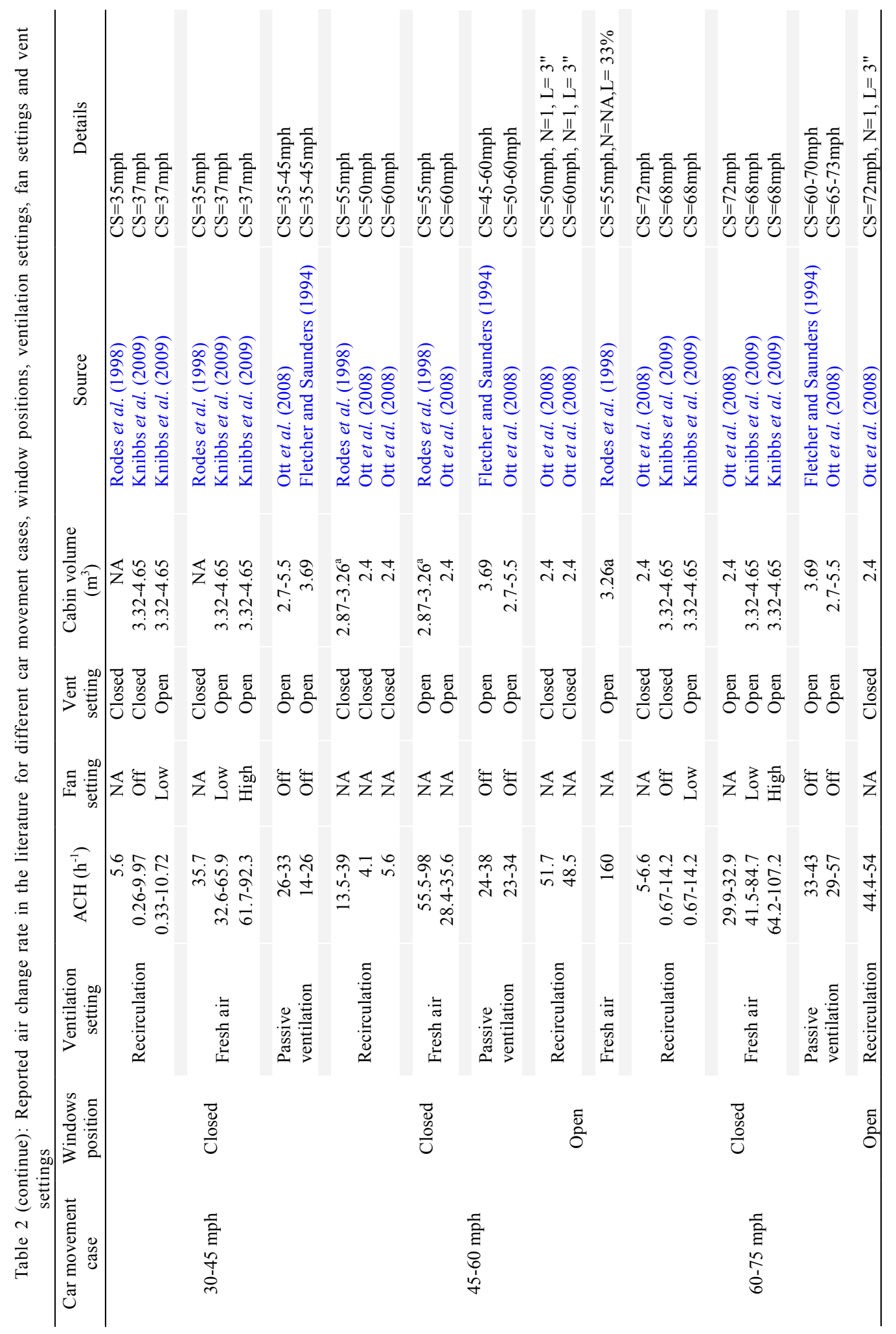


Deposition of the aerosol particles on the interior surfaces of cars is highly dependent on the flow turbulence inside the car. The friction velocity is the key input parameter in the deposition model of Lai and Nazaroff (2000) that characterizes the nature and intensity of near-surface turbulent flow. For chambers with low air change rates, the friction velocity is in the order of $0.1 \mathrm{~m} / \mathrm{s}$ (Lai and Nazaroff, 2005), however in the cabin of cars with high air change rates, the friction velocity is much larger and needs to be determined. The experimental data of Ott et al. (2008) are employed to obtain the friction velocity in each ventilation scenario as explained below.

Ott et al. (2008) reported the deposition rate of the $\mathrm{PM}_{2.5}$ particles for different air change rates in two types of cars (2005 Ford Taurus and 1999 Jeep Cherokee) and found a relationship between the deposition rate $(\hat{a})$ and the air change rate of the cabin as $\hat{a}=1.3 \times A C H$. To estimate the friction velocity, an arbitrary correlation between the friction velocity and the air change rate as the initial guess is used to start with. Next, the deposition velocity for each size category is obtained as the output of the deposition model for various ventilation scenarios. These values are used to calculate the overall deposition rate, the details of which are explained in the next paragraph. The difference between the calculated value of the total deposition rate and the corresponding experimental data of Ott et al. (2008) suggests the correction of the initial guess for the equation relating the friction velocity and the air change rate. This iterative process continues until the calculated value of the total deposition rate matches the experimental data.

The total deposition rate may be obtained from the deposition velocities of all size categories and surface orientations as follows. According to Corner and Pendlebury (1951) the deposition of particles on each surface (vertical, upward horizontal and downward horizontal) is considered to be independent of each other. In the first step, the overall deposition rate for each size category ( $i=1$ to $n$ ) can be obtained by the following equation (Lai and Nazaroff, 2000):

$\beta_{i}=\frac{v_{d v, i} A_{v}+v_{d u h, i} A_{u h}+v_{d d h, i} A_{d h}}{V}$

Where the deposition rate for each size category $\hat{a}_{i}$, is the rate at which the particles deposit on the surface $\left(\mathrm{s}^{-1}\right)$. The quantities $v_{d v, i}, v_{d u h, i}$ and $v_{d d h, i}$ are the deposition velocities on vertical, upward horizontal and downward horizontal surfaces, respectively. $A_{v}, A_{u h}$ and $A_{d h}$ are the total vertical, upward horizontal and downward horizontal surfaces in the cabin of car. In the second step, the overall deposition rate of RSP is calculated based on the portion of each size category in the mass emission rate profile of cigarette smoke as expressed earlier in Fig. 1. The mass emission-weighted average of the deposition rate is estimated by:

$\beta=\frac{\sum_{i=1}^{n} \beta_{i} E_{i}}{E_{\text {total }}}$

Where $\hat{a}$ is the overall deposition rate and $E_{\text {total }}$ is the total mass emission rate of RSP as discussed in section 3.2 .

In Fig. 2, the results of the deposition model and the experimental data of Ott et al. (2008) are compared with each other. The correlation of friction velocity and the air change rate is chosen on a least mean squared basis. It is found that with the linear correlation expressed below, the calculated deposition rate is best fitted to the experiments and the linear regression of reported data. Using a regression analysis the standard deviation of the results of the current model from the above relation has been minimized to obtain a correlation between the friction velocity and the air change rate. By trial and error, the following equation is reached:

$$
\begin{aligned}
& u^{*}\left(\frac{m}{s}\right)=5256 \times \frac{\text { Air Change Rate }\left(\mathrm{s}^{-1}\right)}{\text { Surface-to-Volume Ratio }\left(\mathrm{m}^{-1}\right)} \\
& +4.5\left(\frac{\mathrm{m}}{\mathrm{s}}\right)
\end{aligned}
$$

The effect of the deposition term on the concentration of each size category can be expressed by the following equation:

$$
\frac{d C_{i}}{d t}=-\frac{C_{i}}{V} \times\left(v_{d v, i} A_{v}+v_{d u h, i} A_{u h}+v_{d h, i} A_{d h}\right)
$$

\section{Coagulation model}

In this study, the coagulation of the particles is calculated based on the same approach that was incorporated by Nazaroff and Cass (1989). At first, the collision frequency between two particles is calculated and then these probabilities are integrated to obtain the generation and removal rate for each size category based on the approach developed by Gelbard and Seinfeld (1980). 
The coagulation of submicron particles which mostly occurs by Brownian motion and other mechanisms like gravitational coagulation can be ignored for particles generated by cigarette smoke (Drossinos and Housiadas, 2006). For calculating the collision frequency of particles through Brownian motion, the interpolation formula of Fuchs (1964) is used. After calculating the collision frequency between each two particles, the sectional coagulation model of Gelbard and Seinfeld (1980) is used to determine the source and sink terms in each size category. The mechanism of coagulation acts as a sink for smaller particles and as source for larger particles. More details on this procedure are available in Gelbard and Seinfeld (1980).

\section{Solving the equations}

Once the sink and source terms which are caused by the emission, ventilation, filtration, deposition and coagulation of the particles in the cabin of the cars are specified, the concentration rate for each size category is calculated by the sum of these factors. The general form of the differential equation for each size category, based on the assumptions made in current study, can be expressed as below:

$$
\begin{aligned}
& \frac{d C_{i}}{d t}=S_{E, i}+a_{1, i} C_{i}+a_{2, i} C_{i}^{2}+a_{3, i} C_{i-1}^{2} \\
& +\sum_{j=1}^{n} a_{4, i, j} C_{j} C_{i}+\sum_{j=1}^{i-1} a_{5, i, j} C_{j} C_{i-1}
\end{aligned}
$$

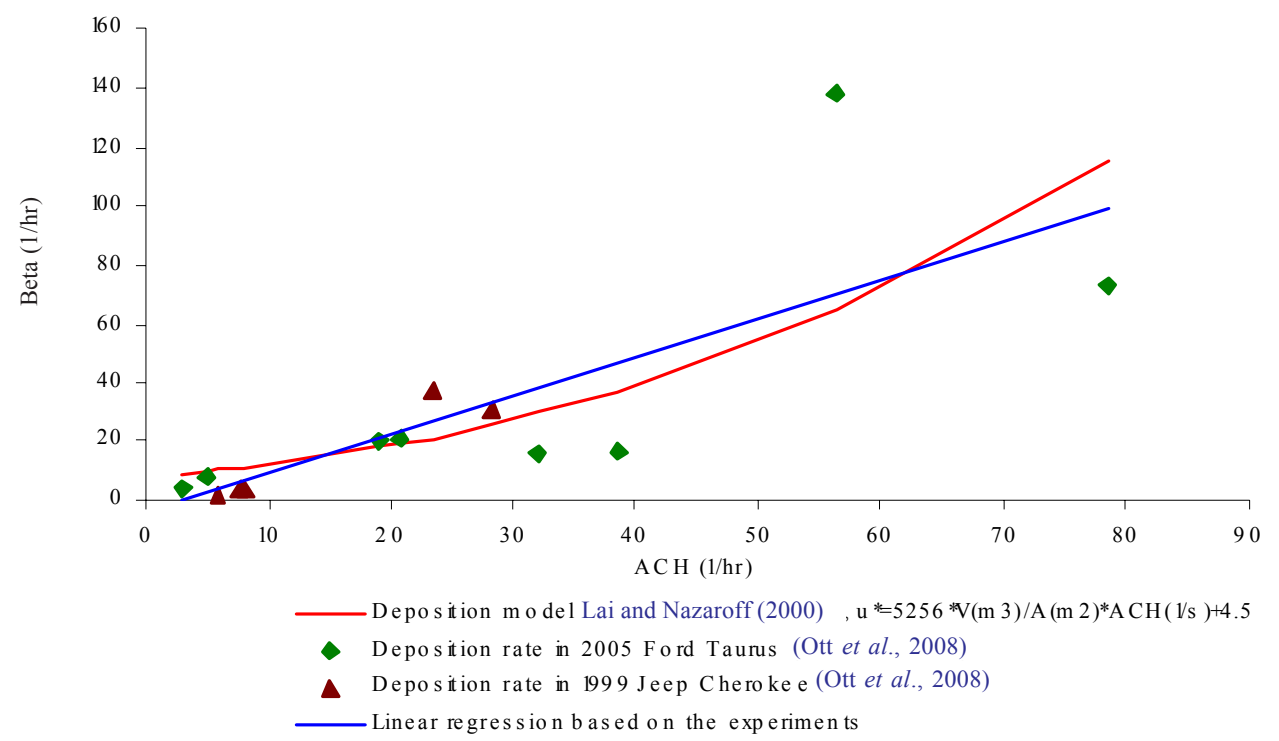

Fig. 2: Prediction of Lai and Nazaroff (2000) deposition model and the measured deposition rate for
Where $a_{1, i}, a_{2, i}, a_{3, i}, a_{4, i, j}$ and $a_{5, i, j}$ are the constant coefficients that were calculated based on the Eqs. 2-7. Since the differential equations of concentration in categories $i=1-\mathrm{n}$ are coupled to each other, these equations must be solved simultaneously. A two-stage implicit Runge-Kutta formula that was proposed by Hosea and Shampine (1996) was used to solve the 8 non-linear differential equations corresponding to the 8 size categories. The density of the particles is assumed to be $1.1 \mathrm{~g} / \mathrm{cm}^{3}$ for all particle sizes (Lipowicz, 1988).

\section{RESULTS AND DISCUSSION}

The cabin volume, cigarette emission scenario and ventilation settings for available data in literature (Table 1) are simulated by the present model and the results are compared against the experiments. In most experimental studies in cars, only the total $\mathrm{PM}_{2.5}$ concentration has been measured and reported. Thus, the predicted concentration of each size category can be integrated over the entire range of particle sizes up to $2.5 \mu \mathrm{m}$ to obtain a value comparable with the total $\mathrm{PM}_{2.5}$ concentrations in the literature.

The scenarios of smoking in cars in various experiments shown in Table 1 (Ott et al., 1992; Ott et al., 2008; Sendzik et al., 2009) are simulated and the results are shown in Figs. 3, 4 and 5. The details of the test conditions may be found in Table 1 as well as from explanations on the figures themselves. It can be seen

\footnotetext{
different air change rate in cars
} 
from Fig. 4 and Fig. 5 that the current model predicts the maximum $\mathrm{PM}_{2.5}$ concentration and also the decay rate of concentration satisfactorily. The experiments of Sendzik et al. (2009), used in Fig. 5 to evaluate the model predictions, do not include the air change rate for different ventilation scenarios. The air change rate data to be used in the current model are extracted from the reported data of other studies listed in Table 2. This may be responsible for some disagreements appearing between the experiments and model predictions in Fig. 5.

In Fig. 3 the predicted RSP concentrations by the mathematical model of Ott et al. (1992) are also shown. Their model is based on the mass balance equation and predicts a bit higher concentration in comparison with the results of the current study. In Fig. 6, the results of the present model are compared with the predicted RSP concentrations by the USEPA Indoor air quality model (IAQ) in a one hour driving simulation presented by Park et al. (1998). That model is also based on the mass balance equation and predicts higher concentrations in comparison with the current study. The similar trend of the variations of RSP concentration suggested by different models shown in Fig. 3 and Fig. 6 may be considered as a qualitative verification of the models' predictions. The minor quantitative discrepancies are most likely due to different emission rates of cigarette smoke being incorporated in the various models.

IAQ model in a one hour driving simulation. The ventilation scenario and car movement cases changed during the smoking and after quitting the smoking. The volume of the car is assumed to be $3.24 \mathrm{~m}^{3}$.

Based on resulting estimates, the extent of health risks due to cigarette smoke in high air change rate chambers like cars may be evaluated for a wide range of ventilation settings and car movement cases. In each case study the value of the air change rate is needed to be specified as an input data for the mathematical model. For this purpose the reported $\mathrm{ACH}$ in the literature (Table 2) for different cases of car movement, window positions, and ventilation settings have been used. $\mathrm{ACH}$ is equivalent to the number of times per hour that the air volume of a given space exchanges with the fresh air. The mean and maximum RSP concentrations due to $6 \mathrm{~min}$ of smoking a cigarette in an ordinary car (cabin volume $=3 \mathrm{~m}^{3}$ ) have been calculated. The results are listed in Table 3 .

To specify the conditions leading to health threats of passengers in cars, the mean RSP concentration is compared with the EPA health-based standard. The recent EPA health-based $\mathrm{PM}_{2.5}$ standard is $35 \mathrm{ì} \mathrm{m}^{-3}$ averaged over $24 \mathrm{~h}$. The predicted mean RSP concentration in each case for a specified period (during

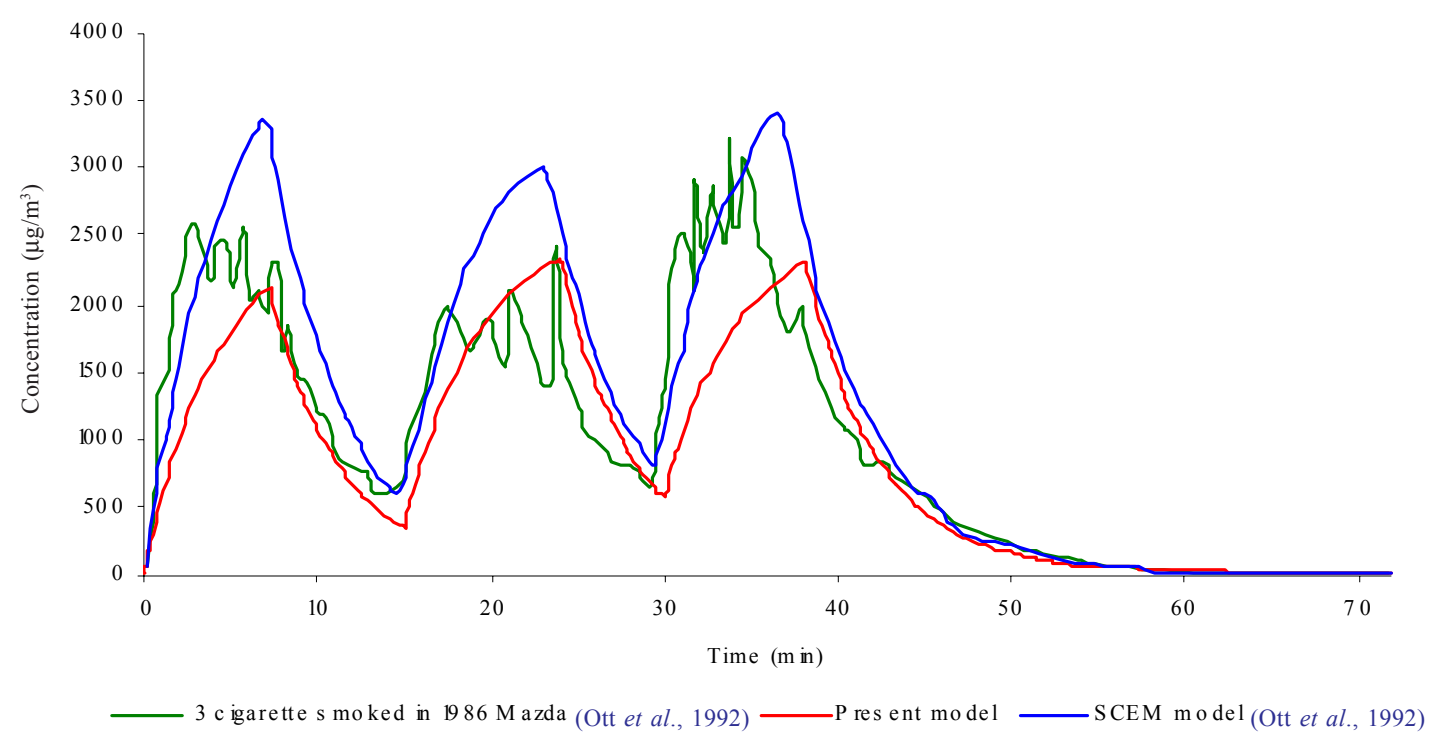

Fig. 3: Comparison of the predicted $\mathrm{PM}_{25}$ mass concentration in 1986 Mazda with experimental data and the mathematical exposure model of Ott et al. (1992). Three cigarettes were smoked when car was driven at $20 \mathrm{mph}$ with closed windows and the air conditioning was set on recycling mode 

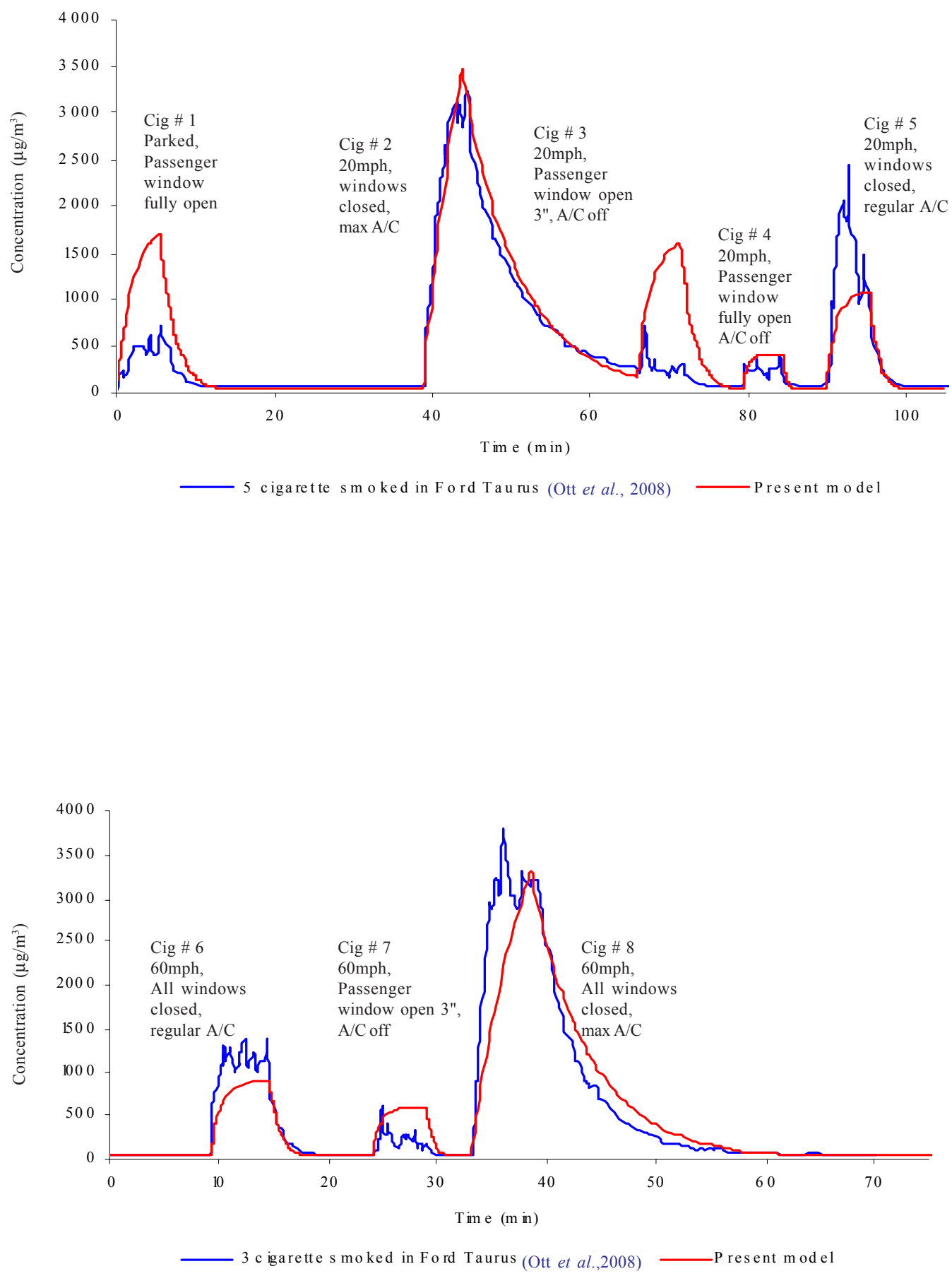

Fig. 4: Comparison of the predicted $\mathrm{PM}_{25}$ mass concentration in 2005 Ford Taurus with experimental data at different speed and ventilation scenarios 

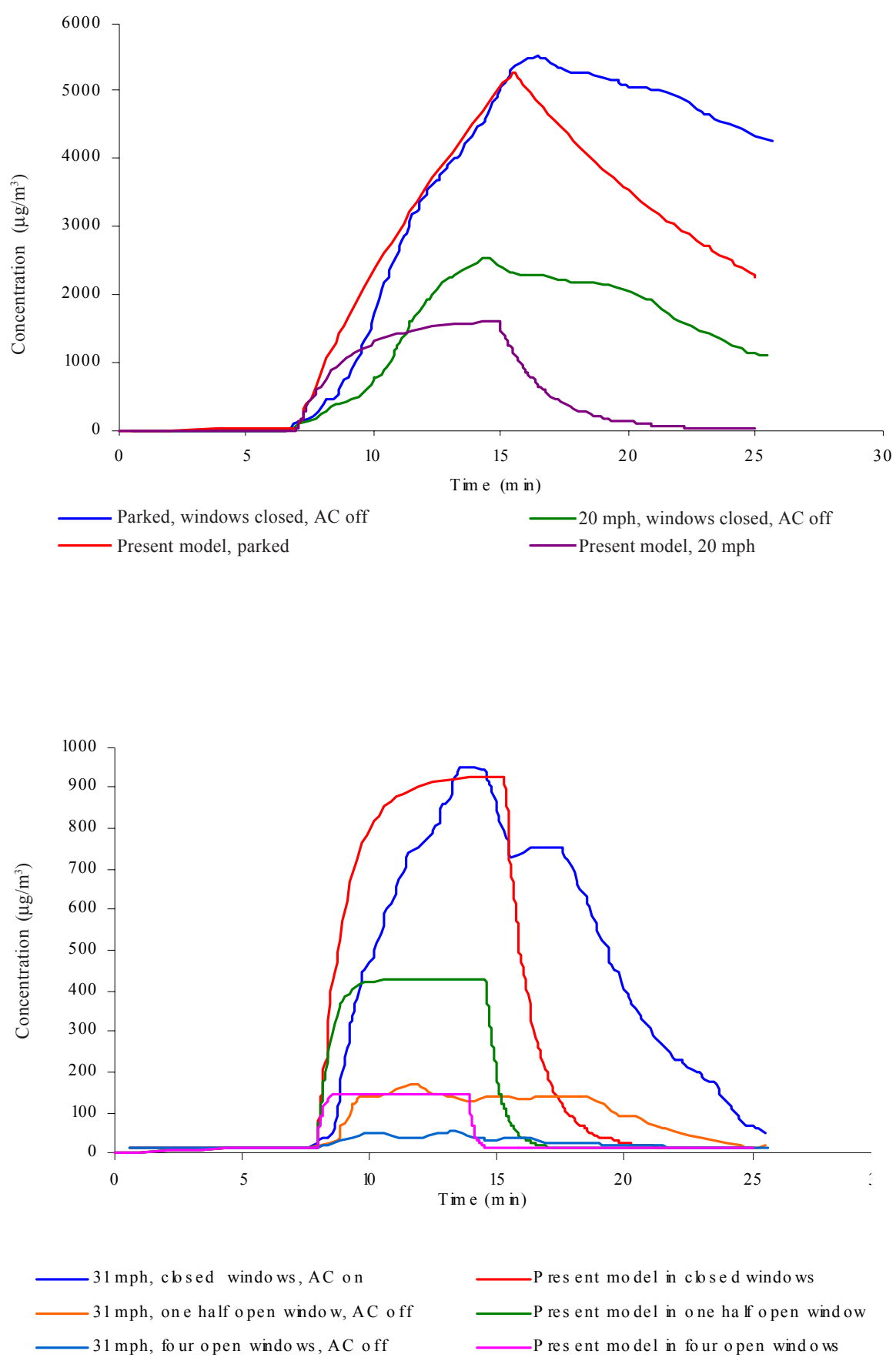

Fig. 5: Comparison of the predicted $\mathrm{PM}_{2.5}$ mass concentration in a car with experimental data in 18 different four-door cars (the cabin average size $=2.6 \mathrm{~m}^{3}$ ). One cigarette was smoked in $25 \mathrm{~min}$ of sampling in different car movement cases and ventilation scenarios 
and after the smoking time until RSP concentration vanishes) is converted into a 24-h incremental exposure $\left(I E_{24}\right)$ by the following equation (Ott et al., 2008). The calculated values of $I E_{24}$ are also listed in Table 3.

$I E_{24}=\bar{x}_{24}=($ Mean concentration $)$

$\times \frac{\text { ETS Exposure period }(\mathrm{min})}{(24 \mathrm{~h} / \text { day })(60 \mathrm{~min} / \mathrm{h})}$

Recirculation of air inside the cabin without major intake of fresh air does not affect the RSP concentration significantly. Another interesting result related to the RSP concentration in stationary cars may be found in the $3^{\text {rd }}$ and $4^{\text {th }}$ lines of the data in Table 3. It can be seen that once the $\mathrm{AC}$ is operating on fresh air mode, the time at which the RSP concentration decreases to its initial value (i.e., before smoking starts) is less than 10 min. however, the time in which the RSP concentration decreases to its initial value for a car with an open window and the $\mathrm{AC}$ off reaches $15 \mathrm{~min}$. Correspondingly, the maximum, mean and $I E_{24}$ values of the RSP concentrations are smaller in the case of the $\mathrm{AC}$ on fresh air mode compared with the case of a window open and the AC off.

For cars in motion, the predicted 24-h incremental exposures due to smoking one single cigarette are generally less than EPA limits. The speed of the car has an important effect on RSP concentrations, especially for open windows and for passive ventilation. The highest RSP concentration values in moving cars are obtained for cases where the ventilation settings are on recirculation. Note that the RSP concentrations listed in Table 3 are calculated based on the smoke emissions of one single cigarette. The values in the table may be multiplied by the number of cigarettes smoked to estimate approximately the concentration of particles. For example, at the speed of 15 to $30 \mathrm{mph}$ with the windows closed and the cabin under passive ventilation, $I E_{24}$ value corresponding to one cigarette smoke is $10.5 \mu \mathrm{g} / \mathrm{m}^{3}$. It means that smoking four cigarettes under same conditions will make $I E_{24}$ reach approximately $42 \mathrm{ig} / \mathrm{m}^{3}$, which is above the EPA $\mathrm{PM}_{2.5}$ limit.

The application of the present model may also enhance our understanding about particle levels and size distributions in automobiles. The predicted mass concentration for each size category when a cigarette is smoked (lasting for $6 \mathrm{~min}$, SS+MS) is shown in Fig. 7. The effect of the cabin ventilation is not considered in this graph and only the mechanisms of emission, deposition and coagulation are taken into account. As shown in Fig. 7, very small $\left(d_{p}<0.1 \mu \mathrm{m}\right)$ and very large $\left(d_{p}>2 \mu \mathrm{m}\right)$ particles have negligible contributions to ETS concentrations during smoking. The midsize particles with $\left(0.4 \mu \mathrm{m}<\mathrm{d}_{\mathrm{p}}<0.6 \mu \mathrm{m}\right)$ remain

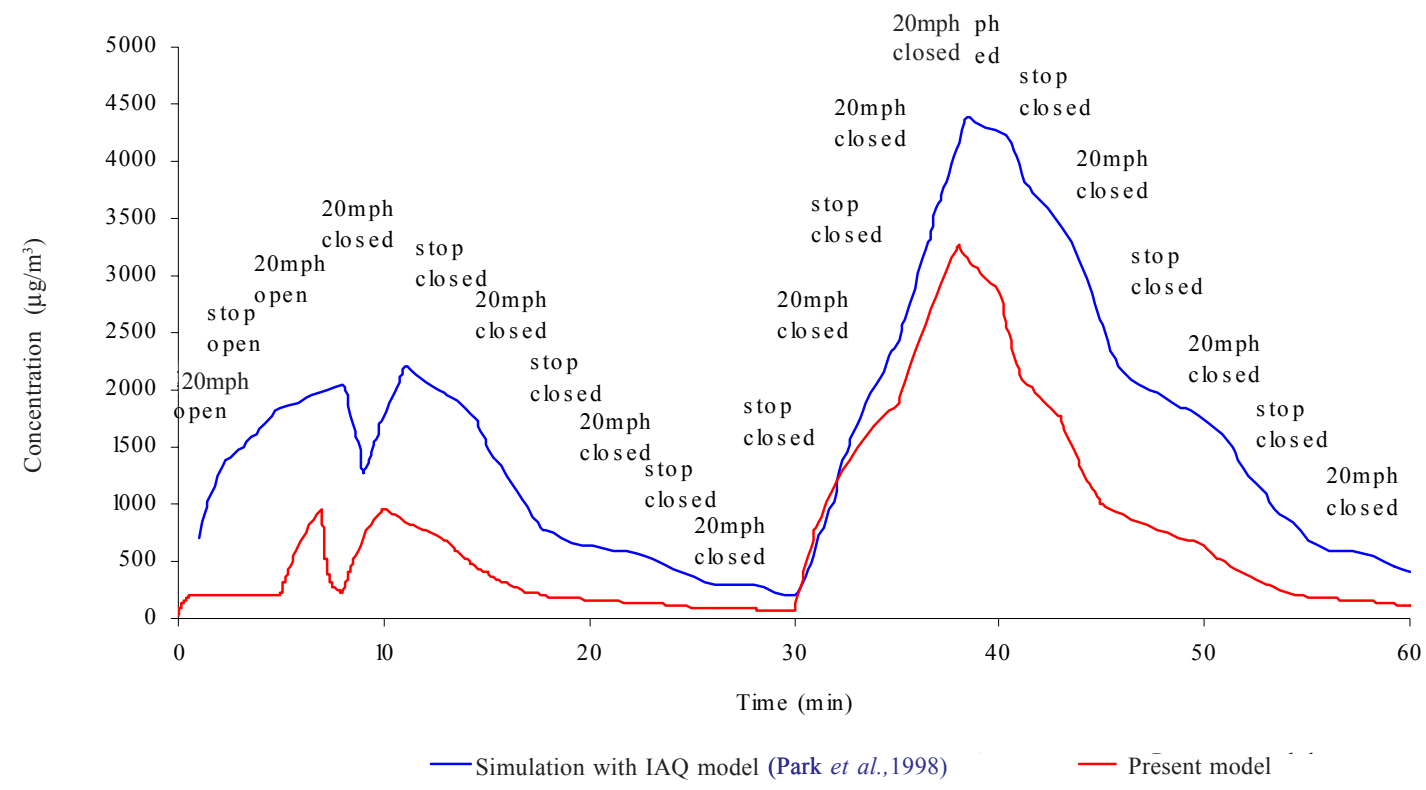

Fig. 6: Comparison of the predicted $\mathrm{PM}_{2.5}$ mass concentration with the results of USEPA indoor air 


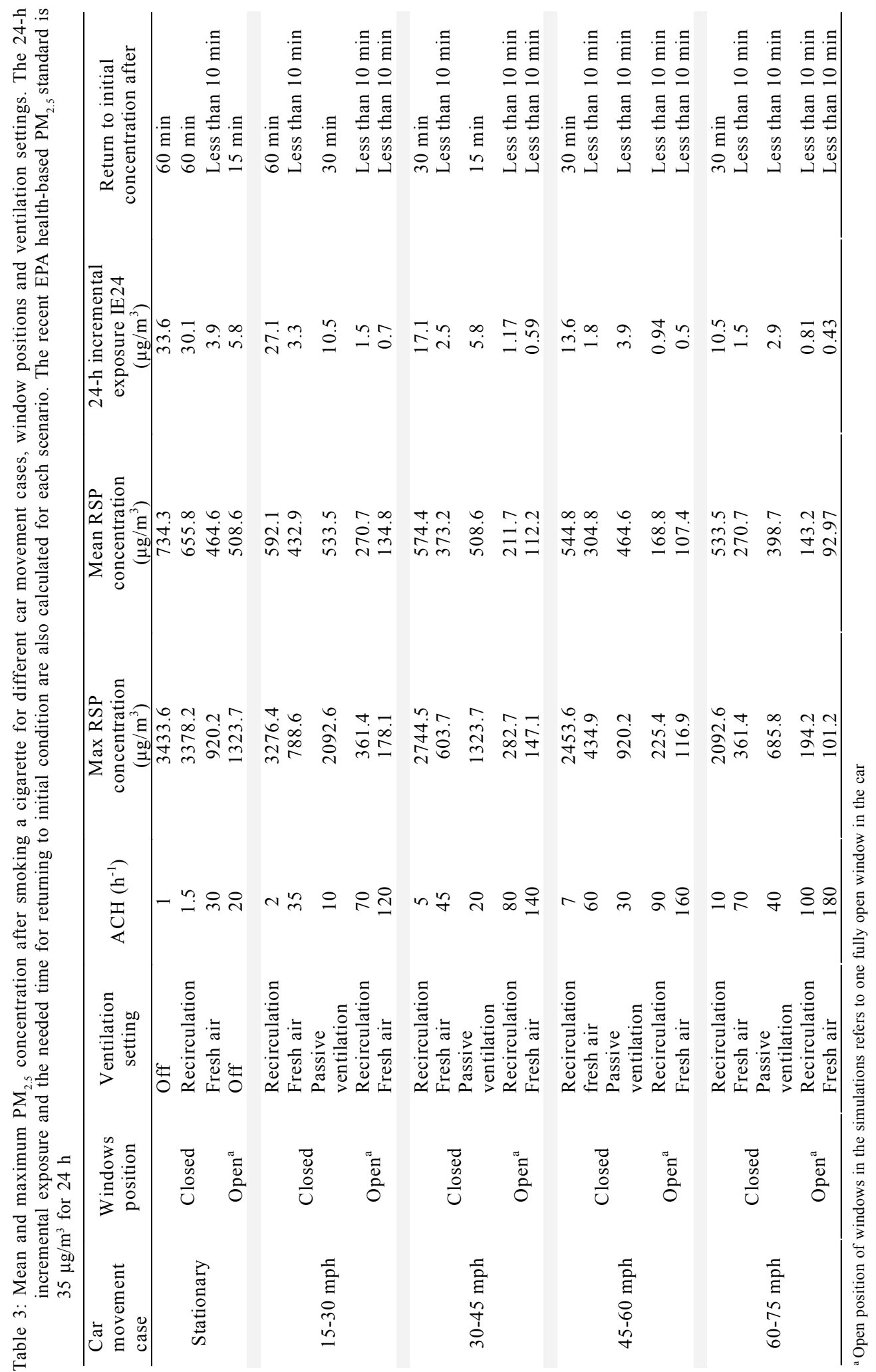


to be the most common particles from the beginning until the end of smoking. This group of particles, as was evident from Fig. 1, has the largest emission rate keep their highest level throughout, and that the deposition and coagulation mechanisms, as sink terms, can not change this order. The size category particles of $0.6 \mu \mathrm{m}<\mathrm{d}_{\mathrm{p}}<1 \mu \mathrm{m}$ which are shown in Fig. 8 to have the second highest concentrations, however, are not the second most emitted particles as seen in Fig. 1. A simultaneous look at Fig. 1 and Fig. 7 may yield more interesting results as for the group of $1 \mu \mathrm{m}<\mathrm{d}_{\mathrm{p}}<2 \mu \mathrm{m}$ particles which have the third highest concentration until the end of the first minute of smoking.
Nevertheless, the sink terms seem to be more effective on this relatively heavy group of particles so that their concentration, as can be seen in Fig. 7, reduces to fifth place.

For better appreciation of particles' behavior shown in Fig. 7, the term concentration rate $E^{\prime}(\mu \mathrm{g} / \mathrm{s})$ is defined for each size category as:

$$
E^{\prime}=\frac{d C_{i}}{d t} \times V
$$

In Fig. 8, the variations of the concentration rate, defined above, are plotted for the 8 size categories as a function of time during which a cigarette is smoked in

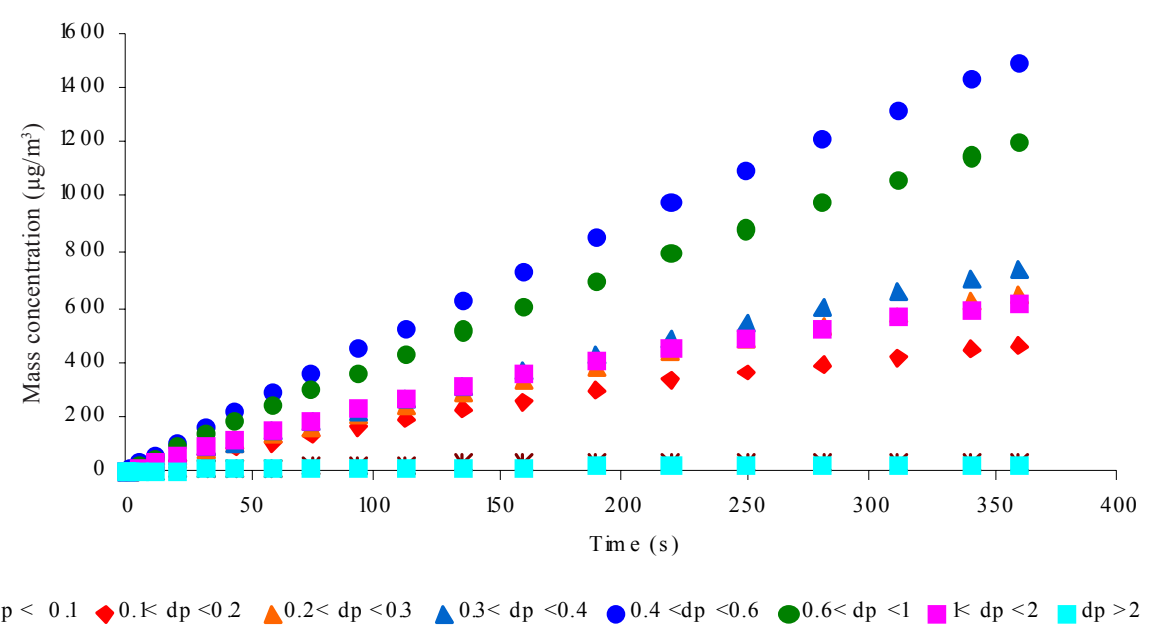

Fig. 7: Predicted mass concentration for 8 size categories after smoking a cigarette in a Daewoo Cielo car as a function of time

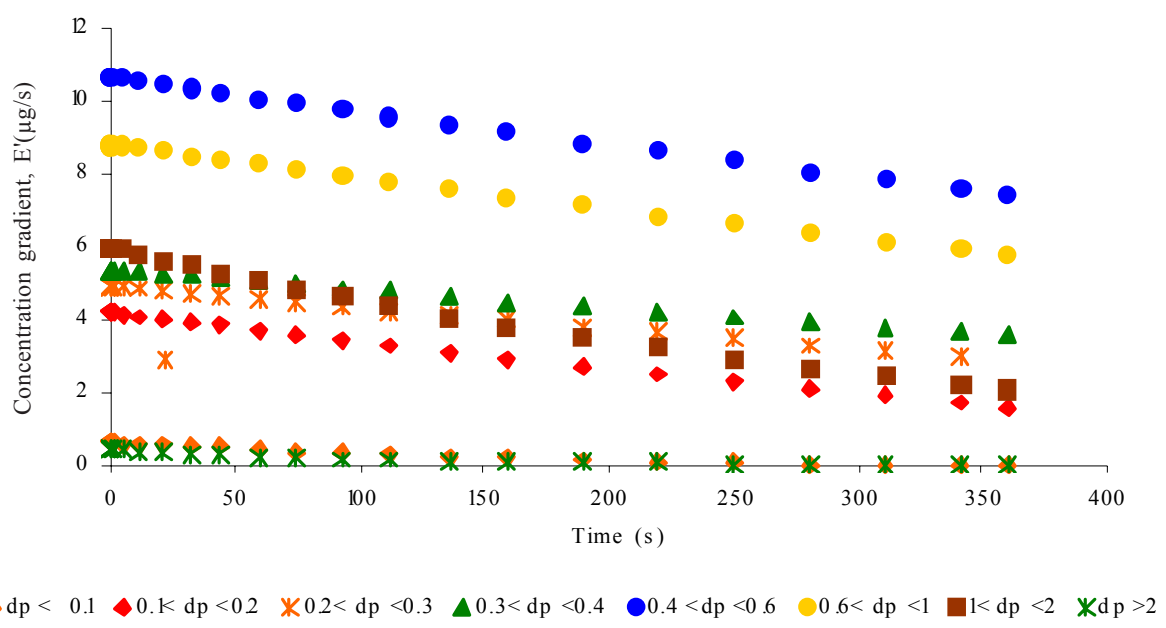

Fig. 8: Variation of the concentration rate for 8 size categories during smoking a cigarette in a Daewoo Cielo car as a function of time 
the cabin of the car. As expected, as the concentration of the particles during smoking increases, the concentration rate decreases with time. The sink term of deposition on the interior surface is proportional to the concentration and increases accordingly. It can also be seen in Fig. 8 that the slope of decrease in the concentration rate is greater for larger particles (compare the graph for 0.2-0.3 $\mu \mathrm{m}$ particles with that of 1-2 $\mu \mathrm{m}$ particles). This can be explained in terms of the deposition rate of particles with different diameters. The reported experiments in the literature (Xu et al., 1994; Long et al., 2001) show a U-shaped type of variations of the deposition rate of particles with the particle size for indoor areas. The smallest deposition rate was reported to occur for particles in the range of $0.2-0.3 \mu \mathrm{m}$. This is quite consistent with the results shown in Fig. 8 in which both the smaller and the larger particle groups demonstrate a steeper gradient of concentration decrease due to greater rates of particle deposition than the $0.2-0.3 \mu \mathrm{m}$ range.

\section{CONCLUSION}

In this study, the dynamic behavior of cigarette smoke particles in a chamber with a high air change rate similar to that of a car has been mathematically modeled. The mathematical model is based on the mass balance equation and the mechanisms of deposition, air exchange, and coagulation of particles are also taken into account. The maximum, mean and $I E_{24}$ concentrations of respirable particles were predicted as functions of time and the size of the particles. Experiments on various smoking scenarios in cars reported by different investigators have been simulated by the current model. In most cases, good agreement between the model predictions and experimental data were reached. Available studies on air change rates for various car speeds, window positions, and ventilation settings are included in the present model. The exposure of the passengers in cars is compared with EPA health-based $\mathrm{PM}_{2.5}$ standards to evaluate probable health risks. Some conclusions reached in this study are as follows:

- In high air change rate chambers like cars, the high friction velocity (i.e., high turbulence intensity) near the walls causes a higher order of deposition velocity in comparison to low air change rate chambers like rooms.
- Based on various ventilation scenarios, the time required for the RSP concentration to return to its initial value before the smoking had started varied between 10 to $60 \mathrm{~min}$. For example, the RSP concentration due to the smoke of a single cigarette in a stationary medium sized car with the AC off becomes negligible after about $1 \mathrm{~h}$. The high RSP concentration in this period of time almost reaches the EPA limits for a $24 \mathrm{~h}$ incremental exposure. Apparently, smoking more than one cigarette under the same conditions will cause a passenger to be exposed to a $\mathrm{PM}_{25}$ concentration above the EPA 24 h standard.

- Recirculation of the air inside the cabin without major intake of fresh air does not affect the RSP concentration significantly and can not reduce the $I E_{24}$ effectively.

- In stationary cars, when the $\mathrm{AC}$ is operating on fresh air mode, the RSP concentration decreases to its initial value faster than when a window is open and the $\mathrm{AC}$ is off.

- The predicted 24-h incremental exposure due to smoking one single cigarette in a moving car is less than the EPA limit for most ventilation scenarios. However, if the number of cigarettes smoked is greater than one, the RSP concentration may exceed the EPA limit. The allowable number of smoked cigarettes can be estimated simply by dividing the EPA limit for $I E_{24}$ concentration by the calculated 24-h incremental exposure in each case.

- The rate of the particle concentration during smoking a cigarette in cars decreases with time due to the effect of the deposition on the surfaces. Since the deposition rate of particles on indoor surfaces shows U-shaped curves and is minimum for particles in the range of $0.2-0.3 \mu \mathrm{m}$, the concentration rate decreases more rapidly for both smaller and larger particles than this range.

More investigation on the efficiency of the filtration in cars and its effect on removing the pollutants is needed. Currently improving ventilation system of cars is being investigated by R\&D departments of many car manufacturers. Furthermore, in the current study it has been assumed that the concentration of particulate matter resulting from smoking cigarettes is evenly distributed within a car cabin. More studies 
which do not make such an assumption are suggested.

\section{ACKNOWLEDGEMENTS}

The authors wish to appreciate support of the Department of Mechanical Engineering, K.N.Toosi University of Technology.

\section{REFERENCES}

Corner, J.; Pendlebury, E. D., (1951). The coagulation and deposition of a stirred aerosol. In Proc. Phys. Soc. B., 64 (8), 645-654 (10 pages).

Drossinos, Y.; Housiadas, C., (2006). Aerosol flows, In: Crowe, C.T., eds., Multiphase flow handbook, CRC Press, Taylor and Francis Group, Boca Raton, FL.

Engelmann, R. J.; Pendergrass, W. R.; White, J. R.; Hall, M . E., (1992). The effectiveness of stationary automobiles as shelters in accidental releases of toxic materials. Atmos. Environ., 26A (17), 3119-3125 (7 pages).

Fletcher, B.; Saunders, C. G., (1994). Air change rates in stationary and moving motor vehicles. J. Hazard. Mater., 38 (2), 243-256 (14 pages).

Fruina, S. A.; Winera, A. M.; Rodes C. E., (2004). Black carbon concentrations in California vehicles and estimation of in-vehicle diesel exhaust particulate matter exposures. Atmos. Environ., 38 (25), 4123-4133 (11 pages).

Fuchs, N. A., (1964). The Mechanics of Aerosols, Dover Publication Inc., New York.

Gao, N. P.; Niu, J. L., (2007). Modeling particle dispersion and deposition in indoor environments. Atmos. Environ., 41 (18), 3862-3876 (15 pages).

Gelbard, F.; Seinfeld, J. H., (1980). Simulation of multicomponent aerosol dynamics. J. Colloid Interf. Sci., 78 (2), 485-501 (17 pages).

Hosea, M. E.; Shampine, L. F., (1996). Analysis and implementation of TR-BDF2. Appl. Numer. Math., 20 (12), 21-37 (17 pages).

Klepeis, N. E.; Ott, W. R.; Switzer, P., (1996). A multiplesmoker model for predicting indoor air quality in public lounges. Environ. Sci. Tech., 30 (9), 2813-2820 (8 pages).

Klepeis, N. E.; Apte, M. G.; Gundel, L. A.; Sextro, R. G.; Nazaroff, W. W., (2003). Determining size specific emission factors for environmental smoke particles. Aerosol Sci. Tech., 37 (10), 780-790 (11 pages).

Klepeis, N. E.; Nazaroff, W. W., (2006). Modeling residential exposure to secondhand tobacco smoke. Atmos. Environ., 40, 4393-4407 (15 pages).

Knibbs, L. D.; De Dear, R. J.; Atkinson, S. E., (2009). Field study of air change and flow rate in six automobiles. Indoor Air, 19 (4), 303-313 (11 pages).

Lai, A. C. K.; Nazaroff, W. W., (2000). Modeling indoor particle deposition from turbulent flow onto smooth surfaces. J. Aerosol Sci., 31 (4), 463-476 (4 pages).

Lai, A.C.K., (2005). Modeling indoor coarse particle deposition onto smooth and rough vertical surfaces. Atmos. Environ., 39 (21), 3823-3830 (8 pages).

Lai, A. C. K.; Nazaroff, W.W., (2005). Supermicron particle deposition from turbulent chamber flow onto smooth and rough vertical surfaces. Atmos. Environ., 39, 4893-4900 (8 pages).

Lipowicz, P. J., (1988). Determination of cigarette smoke particle density from mass and mobility measurements in a millikan cell. J. Aerosol Sci., 19 (5), 587-89 (3 pages).

Long, C. M.; Suh, H. H.; Catalano, P. J.; Koutrakis, P., (2001). Using time- and size-resolved particulate data to quantify indoor penetration and deposition behavior. Environ. Sci. . Tech., 35, 2089-2099 (11 pages).

Maskarinec, M. P.; Jenkins, R. A.; Counts, R. W.; Dindal, A. B., (2000). determination of exposure to environmental tobacco smoke in restaurant and tavern workers in one US city. J. Expo. Analys. Environ. Epid., 10, 36-49 (14 pages).

Miller, S. L.; Nazaroff, W. W., (2001). Environmental tobacco smoke particles in multizone indoor environments. Atmos. Environ., 35, 2053-2067 (15 pages).

Nazaroff, W. W.; Cass, G. R., (1989). Mathematical modeling of indoor aerosol dynamics. Environ. Sci. Tech., 23 (2), 157-166 (10 pages).

Nazaroff, W. W.; Hung, W. Y.; Sasse, A. G. B. M.; Gadgil, A. J., (1993). Predicting Regional Lung Deposition of Environmental Tobacco Smoke Particles. Aerosol Sci. Tech., 19 (3), 243-254 (12 pages).

Nazaroff, W. W.; Klepeis, N., (2003). Environmental Tobacco Smoke Particles, In: Moraswka, L. and Salthammer, T., eds., Indoor Environment: Airborne Particles, and Settled Dust, Wiley-VCH, Weinheim.

Offermann, F. J.; Sextro, R. G.; Fisk, W. J.; Grimsrud, D. T.; Nazaroff, W. W.; Nero, A. V.; Rezvan, K. L.; Yater, J., (1985). Control of respirable particles in indoor air with portable air cleaners. Atmos. Environ., 19 (11), 17611771 (11 pages).

Omidvari, M.; Nouri, J. (2009). Effects of noise pollution on traffic policemen. Int. J. Environ. Res., 3 (4), 645-652. (8 pages)

Ott, W. R.; Langan, L.; Switzer, P., (1992). A time series model for cigarette smoking activity patters: model validation for carbon monoxide and respirable particles in an automobile. J. Expo. Analys. Environ. Epid., 2 (Suppl. 2), 175-200 (26 pages).

Ott, W. R.; Switzer, P.; Robinson, J., (1996). Particle concentrations inside a tavern before and after prohibition of smoking: Evaluating the performance of an indoor air quality model. J. Air Waste Manage. Assoc., 46, 1120-1134 (15 pages).

Ott, W. R.; Klepeis, N.; Switzer, P., (2008). Air change rates of motor vehicles and in-vehicle pollutant concentrations from secondhand smoke. J. Expos. Analys. Environ. Epid., 18 (3), 312-325 (14 pages).

Park, J.; Spengler J. D.; Yoon, D.; Dunnyahn, T.; Lee, K.; Oxkaynak, H., (1998). Measurements of the air exchange rate of stationary vehicles and estimation of in-vehicle exposure. J. Expos. Analys. Environ. Epid., 8 (1), 65-78 (14 pages).

Phillips, K.; Howard, D. A.; Bentley, M. C.; Alvan, G., (1998). Measured exposures by personal monitoring for respirable suspended particles and environmental tobacco smoke of housewives and office workers resident in Bremen, Germany. Int. Arch. Occup. Environ. Health, 71(3), 201-212 (12 pages). 
Pirjola, L.; Parviainen, H.; Hussein, T.; Valli, A.; Hameri, K.; Aaalto, P.; Virtanen, A.; Keskinen, J.; Pakkanen, T.A.; Makela, T.; Hillamo, R. E., (2004). "Sniffer"-a novel tool for chasing vehicles and measuring traffic pollutants. Atmos. Environ., 38 (22), 3625-3635 (11 pages).

Rees, V. W.; Connolly, G. N., (2006). Measuring air quality to protect children from secondhand smoke in cars. Am. J. Prev. Med., 3 (5), 363-368 (6 pages).

Reinhardt, H.; Kobori, S., (2006). The different standard test method for cabin air filters in Japan, USA and Europe, In: 5 th International Filtration Conference, November $7^{\text {th }}-8^{\text {th }}$, Osaka, Japan.

Repace, J., (2007). Exposure to secondhand smoke, In Ott, W. R., Steinemann, A. C. and Wallace, L. A., Exposure Analysis, CRC Press, Boca Raton, FL, p. 214.

Rodes, C.; Sheldon, L.; Whitaker, D.; Clayton, A.; Fitzgerald, K.; Flanagan, J.; DiGenova, F.; Hering, S.; Frazier, C., (1998). Measuring concentrations of selected air pollutants inside California vehicles, Report prepared for California EPA. http://www.arb.ca.gov/research/abstracts/95-339.htm\#Main (accessed 29 Oct, 2009).

Salam, M. A.; Shirasuna, Y.; Hirano, K.; Masunaga, S., (2011). Particle associated polycyclic aromatic hydrocarbons in the atmospheric environment of urban and suburban residential area. Int. J. Environ. Sci. Tech., 8 (2), 255-266 (12 pages).

Sendzik, T.; Fong, G. T.; Travers, M. J.; Hyland, A., (2009).
An Experimental Investigation of Tobacco Smoke Pollution in Cars. Nicotine Tob. Res., 11 (6), 627-634 (8 pages).

Sextro, R. G.; Gross, E.; Nazaroff, W. W., (1991). Determination of emissions profiles for indoor particle phase environmental tobacco smoke. In: 1991 Annual Meeting of the American Association for Aerosol Research, Traverse City, Michigan. Results reported in Nazaroff et al., 1993.

Sohn, M. D.; Apte, M. G.; Sextro, R. G.; Lai, A. C. K., (2007).. Predicting size-resolved particle behavior in multizone buildings. Atmos. Environ., 41 (7), 1473-1482 (10 pages).

Tang, U. W.; Wang, Z., (2006). Determining gaseous emission factors and driver's particle exposures during traffic congestion by vehicle-following measurement techniques. J. Air Waste Manage. Assoc., 56 (11),1532-1539 (8 pages).

Thatcher, T. L.; Lai, A. C. K.; Moreno-Jackson, R.; Sextro, R. G.; Nazaroff, W. W., (2002). Effects of room furnishings and air speed on particle deposition rates indoors. Atmos. Environ., 36 (11), 1811-1819 (9 pages).

Xu, M. D.; Nematollahi, M.; Sextro, R.G.; Gadgil, A. J.; Nazaroff, W. W., (1994). Deposition of tobacco smoke particles in a low ventilation room. Aerosol Sci. Tech., 20 (2), 194-206 (13 pages).

Zhao, B.; Wu, J., (2007). Particle deposition in indoor environments: Analysis of influencing factors. J. Hazard. Mater., 147 (1-2), 439-448 (10 pages).

\section{AUTHOR (S) BIOSKETCHES}

Saber. E. M., M.Sc., Department of Mechanical Engineering, K.N.Toosi University of Technology, Tehran, Iran.

Email: mahmoudi_mech@yahoo.com

Bazargan, M., Ph.D., Department of Mechanical Engineering, K.N.Toosi University of Technology, Tehran, Iran.

Email: bazargan@kntu.ac.ir

Saber, E. M.; Bazargan, M., (2011). Dynamic behavior modeling of cigarette smoke particles inside the car cabin with different ventilation scenarios. Int. J. Environ. Sci. Tech., 8 (4), 747-764. 